CO-PIRÓLISE DE RESÍDUO DE POLIETILENO COM GASÓLEO DA BACIA DE CAMPOS

\title{
CO-PYROLYSIS OF POLYETHYLENE'S WASTE WITH BACIA DE CAMPOS'S GASOIL
}

\author{
CARNEIRO, Débora da Silva ${ }^{1}$; MARQUES, Mônica Regina da Costa ${ }^{1}$; \\ ${ }^{1}$ Universidade do Estado do Rio de Janeiro, Instituto de Química, Laboratório de Tecnologia Ambiental, R. São \\ Francisco Xavier, 524, Pavilhão Haroldo Lisboa da Cunha, $3^{\circ}$ Andar, CEP 20559-900, Rio de Janeiro - RJ, \\ Brasil \\ e-mail: monica@pesquisador.cnpq.br
}

Received 4 July 2009; received in revised form 24 November 2009; accepted 24 December 2009

\section{RESUMO}

Nesse trabalho foi realizado o processo de co-pirólise de resíduo de plástico de polietileno com gasóleo, numa temperatura de $550^{\circ} \mathrm{C}$. Primeiramente, as amostras de polietileno e gasóleo foram submetidas a co-pirólise térmica em atmosfera inerte. Depois, foi avaliada a eficiência do processo com variação da quantidade de resíduo de polietileno adicionada ao gasóleo. Os líquidos pirolíticos gerados foram caracterizados por cromatografia gasosa modificada, com o objetivo de avaliar a geração de frações na faixa da destilação do diesel. Pode-se observar que o aumento da quantidade de PE no meio reacional favorece a redução do rendimento de líquido pirolítico e o aumento da quantidade de sólido gerado. Os resultados obtidos comprovam o potencial da co-pirólise como método de reciclagem química de artefatos de polietileno pósconsumo.

Palavras-chave: resíduos, polietileno, co-pirólise

\begin{abstract}
In this work the process of co-pyrolysis of polyethylene plastic residue was carried through with petroleum, in a temperature of $550^{\circ} \mathrm{C}$. First, the polyethylene samples and petroleum had been submitted the thermal co-pyrolysis in inert atmosphere. Later they had been evaluated the efficiency of the process with variation of the amount of polyethylene residue added to the petroleum. The generated pyrolytic liquids had been characterized by modified gaseous chromatography, with the objective to evaluate the generation of fractions in the band of the distillation of diesel. It can be observed that the increase of the amount of PE in the half reactional favors the reduction of the income of pyrolytic liquid and the increase of the amount of generate solid. The results show that plastic residue co-pyrolysys is a potential method for chemical recycling of plastic products.
\end{abstract}

Keywords: waste, polyethylene, co-pyrolysis 


\section{Introdução}

Os plásticos são usados em grande escala na produção de embalagens, principalmente em produtos descartáveis, utensílios domésticos e eletrodomésticos, além de suas aplicações científico-tecnológicas e em diversas áreas da indústria. A popularização dos plásticos se deve, basicamente, ao seu baixo custo de produção, peso reduzido, elevada resistência e à possibilidade de seu uso na fabricação de peças nas mais variadas formas, tamanhos e cores, e com os mais diversos requisitos de especificação (transparência, dureza etc.) (DE SOUZA, 2002).

A demanda de materiais plásticos no mundo vem crescendo a taxas altíssimas, acima da taxa de crescimento do produto interno bruto (PIB) de alguns países. Os dados de NEGRI BOSSI (2004) apresentam projeções de demanda que indicam uma taxa de crescimento na ordem de $20 \%$ para o período de 2004 a 2009.

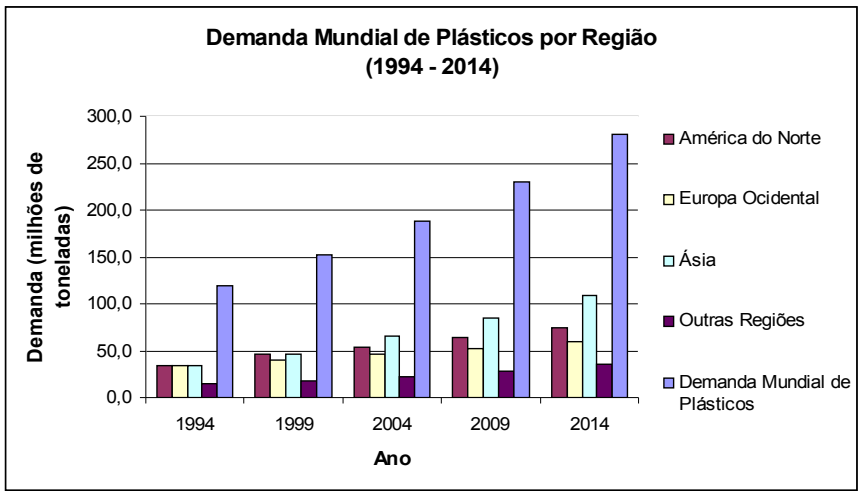

Figura 1 - Demanda Mundial de Plásticos por Região no período de 1994 a 2014 (NEGRI BOSSI, 2004).

No Brasil, o consumo aparente de plásticos em 2007 foi de 4,8 milhões de toneladas, mantendo uma tendência de crescimento, conforme apresentado na Figura 2, em mil toneladas.

A perspectiva de maior crescimento da economia e o reduzido grau de consumo per capita de plásticos no país apontam para um leque de possibilidades do setor. O consumo de plásticos per capita, em 2006, alcançou em 24,4 $\mathrm{kg}$ por habitante, inferior à média mundial e cerca de um quarto daquele verificado nos Estados Unidos (UNICAMP, 2008).

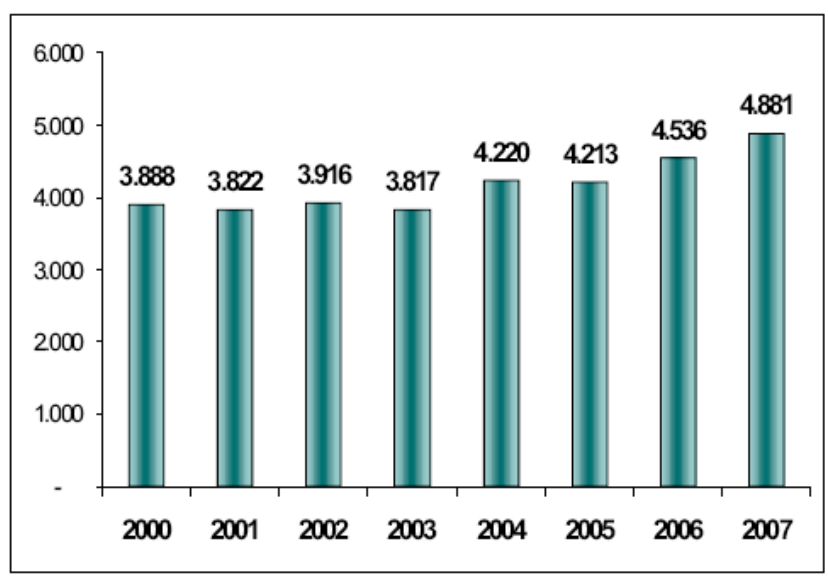

Figura 2 - Consumo aparente de resinas plásticas no Brasil, em mil toneladas (DE PAOLI, 2008).

O setor de embalagens (incluindo o setor alimentício) é o que representa a maior fatia de mercado dos plásticos. No ano de 2005, esse setor teve uma receita $R \$ 10$ milhões, com um crescimento previsto para 2006 de 3\% (ABRE, 2006).

O status atual de desenvolvimento requer uma igualdade nos pesos dos dois lados da balança. De um lado, está a sociedade em crescimento que requer a manutenção e/ou aumento dos níveis atuais de consumo de plásticos para não afetar a qualidade de vida alcançada. Do outro lado, está a biodiversidade e as condições ambientais que já estão sofrendo os efeitos desse cenário, uma vez que os resíduos plásticos representam uma fatia significativa do resíduo sólido mundial (MANCINI; ZANIN, 2004).

A "não degradabilidade" no ambiente e a vida útil muito curta dos artefatos plásticos torna seu uso questionável em termos ambientais. Uma vez dispostos no meio ambiente, tais materiais ocupam um considerável espaço, diminuindo o tempo de vida de aterros e lixões e agravando o problema da saúde pública nos centros urbanos. O plástico não é apenas um material de difícil decomposição nos aterros como também prejudica a degradação de outros materiais por criar camadas impermeáveis entre a terra e os resíduos, dificultando a circulação de ar nestes ambientes (Pro teste, 2006). Além disso, o avanço das legislações a nível nacional e internacional tem levado os produtores e processadores de resinas plásticas investirem 
em tecnologias de reaproveitamento reciclagem dos plásticos pós-consumo.

Dentro das tecnologias estudadas, destaca-se a pirólise onde ocorre a decomposição térmica do polímero, produzindo conforme o caso, os monômeros de origem ou moléculas orgânicas com alto poder calorífico que podem ser utilizadas como combustível (CARNEIRO, 2007, KAMINSKY; SCHEIRS, 2006).

Mundialmente, existem vários exemplos de sistemas pirolíticos em operação com diferentes tipos de tecnologias aplicadas para a retirada de produtos do processo. A transformação dos resíduos em subprodutos ocorre gradualmente à medida que os resíduos sólidos passam pelas diversas zonas de calor que constituem o reator pirolítico. Estados Unidos, Japão e China são os países que mais têm investido em pesquisa na área de pirólise, destacando-se a China em número de patentes depositadas (DE OLIVEIRA et al., 2008).

Segundo Aires e colaboradores (2003), a pirólise pode ser classificada em sistemas de alta temperatura e sistemas convencionais (baixa temperatura), em função das características dos processos.

Os sistemas convencionais podem ainda ser divididos em duas categorias: os destinados a produzir combustíveis gasosos e os de produção de combustíveis líquidos. A pirólise a baixas temperaturas promove predominantemente a despolimerização dos plásticos, isto é, o rompimento das cadeias poliméricas. (ROCHA; PÉREZ; CORTEZ, 2004).

Os principais produtos do processo de pirólise são (MENEZES, 1999):

- gases, constituídos principalmente de hidrogênio, metano, monóxido de carbono, hidrocarbonetos leves e outros;

- líquidos, constituídos basicamente de hidrocarbonetos, álcoois e ácidos orgânicos;

- resíduos sólidos, constituídos por carbono quase puro (char) e vidro, metais e outros materiais inertes (escórias).

Fatores como tipo de resíduos, tamanho das partículas submetidas ao processo, tipo de reator, temperatura e velocidade de variação da temperatura, cinética do processo, umidade presente nos resíduos, dentre outros, têm sido estudados como fatores que influenciam no processo pirolítico e nos subprodutos obtidos pelo tratamento (DE OLIVEIRA, 2006).

A co-pirólise é adição de mais de um material como carga no reator pirolítico. As vantagens estão relacionadas às condições de processamento (temperatura e pressão) que podem ser reduzidas. Segundo Miller e Shan (2000), a co-pirólise de poliolefinas com outros combustíveis tem se mostrado tecnicamente viável.

O objetivo geral desse trabalho é utilizar a técnica de co-pirólise de resíduos plásticos de polietileno pós-consumo com gasóleo, visando à obtenção de hidrocarbonetos da fração óleo diesel.

\section{Materiais e Métodos}

As amostras de polietileno (PE) pósconsumo (frascos de água para injeção, conforme Figura 3) foram picotadas manualmente e utilizadas sem nenhum tratamento prévio. A amostra de gasóleo foi doada pelo Centro de Pesquisas da Petrobras (Cenpes). Esta amostra foi extraída do campo de Marlin localizado na Bacia de Campos, do tipo e é considerada um óleo pesado de alta viscosidade.

A avaliação térmica das amostras de PE pós-consumo foi feita em instrumento TG da marca TA Instruments, modelo Q50, calibrado antes das análises com amostras-padrão de Alumel e Níquel, à mesma velocidade de aquecimento a que seriam submetidas as amostras. As análises das amostras, com massas entre 5 e $10 \mathrm{mg}$ de PE pós-consumo, foram realizadas por meio de uma rampa de aquecimento de 50 à $750{ }^{\circ} \mathrm{C}$ à velocidade de 10 ${ }^{\circ} \mathrm{C} / \mathrm{min}$ em cadinho de platina, sob atmosfera de nitrogênio à vazão de $100,0 \mathrm{~mL} / \mathrm{min}$. A avaliação termogravimétrica das amostras seguiu as diretrizes estabelecidas na norma técnica ASTM E-1868-04.

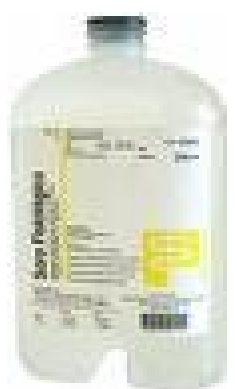

Figura 3 - Foto da amostra de PE pósconsumo utilizada neste estudo. 
A caracterização química da amostra de PE pós-consumo foi feita por espectroscopia de infravermelho de reflexão total atenuada (IRATR) em instrumento Perkin Elmer Spectrum One FTIR, com acumulação de 32 espectros e resolução de $4 \mathrm{~cm}^{-1}$.

As amostras de polietileno pós-consumo foram co-pirolisadas na presença de gasóleo em esquema adaptado da unidade de Teste de Micro Atividade (MAT), doada pelo CENPES para avaliação do processo de craqueamento de gasóleo em leito fixo (Figura 4).

Essa unidade é um sistema integrado para a realização de pirólise sob fluxo de nitrogênio, constituído basicamente de reator cilíndrico, fornalha, condensador de vidro e vaso recolhedor. Durante a pirólise da amostra contida no reator, o líquido combustível é recolhido por meio de imersão do condensador de vidro em banho de gelo e o gás combustível em vaso recolhedor. O sistema opera com base nas normas do Standard Test Procedure estabelecida no ASTM D 3907-92.

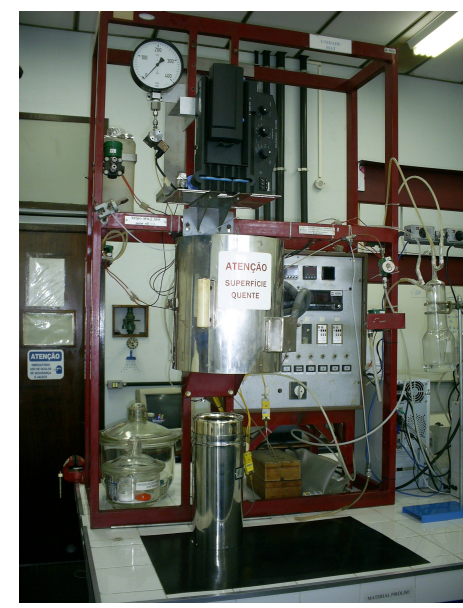

Figura 4 - Foto da Unidade MAT utilizada nos testes de co-pirólise de polipropileno e gasóleo.

As amostras de polietileno pós-consumo foram pesadas, variando-se de $0,1 \mathrm{~g}$ até $1,0 \mathrm{~g}$ de PE. Paralelamente, pesou-se $1,0 \mathrm{~g}$ de gasóleo, mantendo-se esta quantidade em todos os testes de co-pirólise, inclusive aqueles onde não se adicionou o PE. Pesou-se o reator vazio antes e após os experimentos para cálculos do resíduo gerado e de perdas do processo.

Transferiu-se o líquido do condensador de vidro para um frasco de amostragem, acrescentando-se $2 \mathrm{~mL}$ de n-hexano. As amostras foram armazenadas sob refrigeração à $4^{\circ} \mathrm{C}$, evitando, desta forma, perdas por volatilização.

O efluente gasoso e o resíduo sólido obtidos na pirólise não foram analisados no estudo. Os líquidos da pirólise foram analisados por cromatografia em fase gasosa modificada. Os testes de pirólise foram realizados em duplicata $e$, caso houvesse divergência dos resultados, uma terceira análise foi realizada.

As análises do líquido pirolítico formado foram realizadas por destilação simulada de alta temperatura por cromatografia gasosa (High Temperature Simulated Destillation - HTSD), em cromatógrafo gasoso modificado, equipamento AC High Temp SIMDIS Analyzer, modelo HT750, com coluna capilar, seguindo metodologia ASTM D 7169 (Standard Test Method for Boiling Point Distribution of Samples with Residues Such as Crude Oils and Atmospheric and Vacuum Residues by High Temperature Gas Chromatography).

Esta metodologia permite a determinação da distribuição dos pontos de ebulição de frações residuais até cerca de $720{ }^{\circ} \mathrm{C}$, permitindo a análise de compostos com até 100 carbonos na composição, o que a torna mais adequada para amostras de composição desconhecida (AC ANALYTICAL CONTROLS, 2008). É utilizada para a determinação da distribuição de pontos de ebulição de amostras de resíduos atmosféricos, resíduos de vácuo etc (PINTO, 2002).

\section{Resultados e Discussão}

As análises de TGA foram determinantes na escolha da faixa de temperatura a ser utilizada nos testes de co-pirólise de PE com gasóleo.

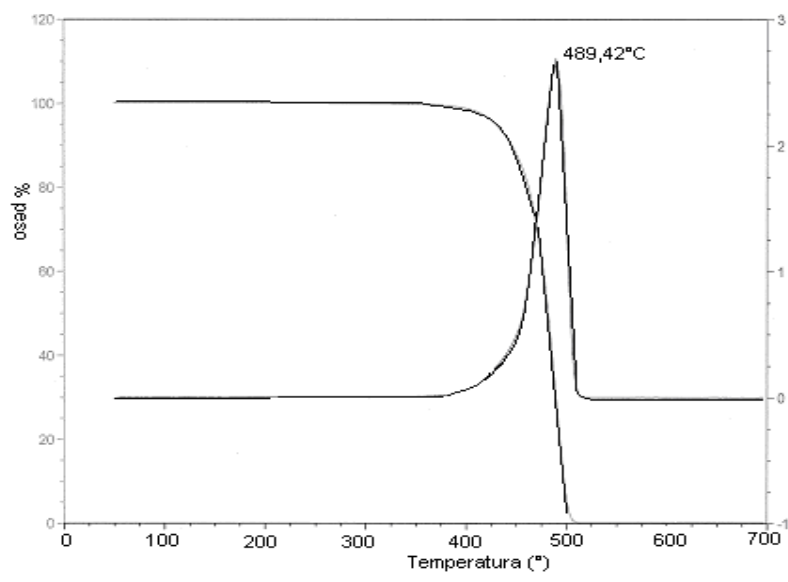

Figura 5 - Curva de TG/ dTG do resíduo plástico pós-consumo. 
As análises de infravermelho foram importantes na identificação das bandas presentes nas amostras de PE pós-consumo que, pelo perfil dos espectros apresentados, indicam uma elevada pureza das amostras devido à preservação das características das bandas, que é típica de hidrocarbonetos alifáticos com cadeias de sete ou mais átomos de carbono.

Os testes de co-pirólise de PE com gasóleo forneceram resultados interessantes para este trabalho.

Os líquidos pirolíticos obtido nas copirólises de PE com gasóleo foram submetidos a cromatografia gasosa de alta resolução (CGAR), com o objetivo de se determinar o teor de hidrocarbonetos da fração óleo diesel presente no líquido pirolítico.

De acordo com os resultados apresentados, o aumento da quantidade de resíduos plásticos ao gasóleo favoreceu o aumento da geração de líquido pirolítico e a redução do sólido formado.

A Figura 6 abaixo apresenta os resultados o efeito da massa no rendimento de líquido pirolítico formado.

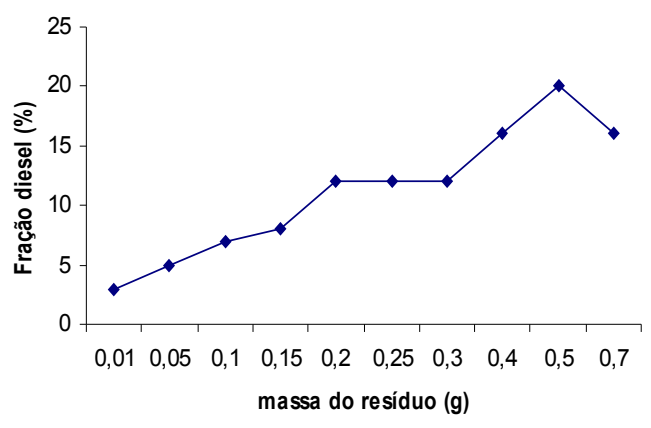

Figura 6 - Efeito da massa de resíduo no rendimento do líquido pirolítico formado.

Como pode ser visualizado, existe um limite de resíduo que pode ser usado para ser pirolisado com gasóleo nesse sistema e nas condições desse estudo. O que foi observado no experimento da amostra PI 0,70, é que durante os 15 minutos de corrida, o líquido pirolítico era bastante viscoso e também era formada uma cera de odor marcante, sugerindo ser parafina.

\section{Conclusões}

Os resultados do estudo indicam que a tecnologia de tratamento térmico por co-pirólise é válida para o tratamento de resíduos de PE, pois, além de minimizar o impacto ambiental causado pela disposição desse material de maneira inadequada, permite um melhor aproveitamento de um recurso natural não-renovável, o petróleo, através das frações obtidas no processo.

\section{Agradecimentos}

Ao CNPq, FAPERJ e PETROBRAS pelo

suporte financeiro e ao CNPq pela bolsa de apoio técnico de Caneiro, D.S.

\section{Referências}

1) ASSOCIAÇÃO BRASILEIRA DE EMBALAGEM (ABRE). Informações sobre a Indústria de brasileira de Embalagens. Disponível em: <http://www.abre.org.br/index.php>. Acesso em: 4 nov. 2006.

2) CARNEIRO, D. S. Co-Pirólise de resíduos de polietileno com gás-óleo da Bacia de Campos. 2007. 91f. Dissertação (Mestrado em Química) Universidade do Estado do Rio de Janeiro, UERJ, RJ.

3) CIOCÎLTEU, S.; DARIE, H.; IOJOIU, E.; ONU, P.; VASILE, C. Thermal and catalytic decomposition of polyethylene and polypropylene. Journal of Analytical and Applied Pyrolylis, [S.I.], v. 49, p.145-153, 1999.

4) DE OLIVEIRA, O. M. C.; DE SENA, A. R.; PEREIRA, L. A. G.; RODRIGUES, L.M. Reciclagem Química de Polímeros. 2008. 76f. Monografia (Especialização em Engenharia de Processamento de Petróleo) - Universidade Estadual do Rio de Janeiro, UERJ; Petróleo Brasileiro S.A. - PETROBRAS. Rio de Janeiro.

5) DE OLIVEIRA, M. L. Caracterização e Pirólise de Resíduos da Bacia de Campos: Análise dos Resíduos da P40. 2006. 192 f. Dissertação (Mestrado em Química) - Universidade do Estado do Rio de Janeiro, UERJ. Rio de Janeiro. 
6) DE PAOLI, M. A. Reciclagem Mecânica de Polímeros. In: I Seminário Reciclagem de Polímeros PETROBRAS. Rio de Janeiro, s.n., 2008.

7) $\mathrm{DE}$ SOUZA, M. C. A. F. Estudo da Competitividade de Cadeias Integradas no Brasil: impactos das zonas de livre comércio. Nota Técnica Final, UNICAMP-IE-NEIT / MDIC / MCT / FINEP, São Paulo, SP, 2002.

8) KAMINSKY, W.; SCHEIRS, J. Feedstock Recycling and Pyrolysis of Waste Plastics: Converting Waste Plastics into Diesel and Other Fuels. Ed. John Wiley \& Sons, [S.I.], s.n., 2006.

9) MANCINI, S. D.; ZANIN, M. Resíduos Plásticos e Reciclagem: Aspectos Gerais e Tecnologia. EdUFSCar: São Carlos, SP, 143p., 2004.

10) MENEZES, R. A. Análise de projetos de tratamento por destruição térmica de resíduos sólidos urbanos e especiais. indicadores operacionais. Curso ABS/CEF, [S.I.], s.n., 1999. Disponível em:

$<$ http://www.kompac.com.br/publicacoes/e stado.htm>. Acesso em: 25 mar. 2008.

11) MILLER, S. J.; SHAH, N. Method for conversion of waste plastic to lube oil. United States Patent 6150577. USA, $2000 . \quad$ Disponível em: <http://www.freepatentsonline.com/61505 77.html>. Acesso em: 3 maio 2008.

12) NEGRI BOSSI. Editorial. Informações sobre demanda mundial de plásticos. [S.I.], 2004. Disponível em: <http://www.negribossi.com/System/8840/ 633481148125046232itIT.pdf>. Acesso em: 10 jun. 2008.

13) PINTO, U. B. Uso da Técnica de Destilação Simulada de Alta Temperatura para Extrapolação da Curva de Ponto de Ebulição Verdadeiro de Petróleos. Boletim Técnico Petrobras, Rio de Janeiro, RJ, v. 45, p. 343-349, 2002. Disponível em: <http://www2.petrobras.com.br/tecnologia/ port/boletim_tecnico/v45_n3-4_jul-dez2002/pdf/8.pdf>. Acesso em: 15 jun. 2008.

14) Revista Pro Teste. Um material $100 \%$ reutilizável. n. 51. p. 23. Setembro 2006.

15) ROCHA, J. D.; PÉREZ, J. M.; CORTEZ, L. A. B. Aspectos Teóricos e Práticos do Processo de Pirólise de Biomassa. [Campinas, SP], s.n., 2004. Disponível em: <http://www.bioware.com.br>. Acesso em: 26 mar. 2008.

16) UNICAMP. Unicamp e ABDI lançam Boletim de Conjuntura Industrial. São Paulo, SP, 2008. Disponível em: <http://www.unicamp.br/unicamp/divulgac ao/BDNUH/NUH_10294/NUH_10294.html >. Acesso em: 11 jun. 2008. 